\title{
The application of government data in retail business location planning
}

Recerved-14 April 2005

\begin{abstract}
James Nolan
has used location planning techniques to support development projects for a number of companies in the UK and overseas. His career began working with geographical information systems in research and development, before applying skills in software and computer-modelling applications within the commercial sector. He has worked with discount and convenience food retailers, high-street leisure operators and variety retailers.
\end{abstract}

\begin{abstract}
The release of the UK's 2001 population Census data, and advances in computing technology used in their analysis, have increased the application of statistics in retail business development. A number of innovations have added to the quality and types of data that are now available. This paper outlines some of the advantages gained in testing raw data as they were released, and points to how future outputs may be adopted for use in retail planning.
\end{abstract}

\section{Keywords:}

geographical information, demographics, location planning

\section{GEOGRAPHY AND RETAIL BUSINESS}

Geographical information systems (GIS) are databases that allow the integration of data for analysis and presentation. They are used in business to solve problems which concern location, and to assist decision making using geographically referenced data. Retailers have long been using these systems to assist in the siting of stores and to understand the interaction of high-street shops with their surrounding competition and with probable areas of profitable development. Here is an example of how, with the use of a GIS, the 2001 Census data can be applied in a range of retail business applications.

\section{BUSINESS USE OF CENSUS DATA IN THE UK}

The discipline of geographical analysis has long attracted the attention of retailers, market researchers and analysts who use Census variables. With the recent release of Census statistics, this aspect of retail planning has been given a new set of tools with which businesses can measure market characteristics and target investment throughout the UK. The Census release has provided those working in retail planning with the opportunity to update 


\section{Geographical business data}

\section{A new geography}

Scale of application existing databases, review Census-derived products and develop and use new analysis techniques.

In many retail businesses, high volumes of data are collected and analysed to support the aims of the company. Much of these data may not be considered geographical, but they can be used to assist in optimising business performance. The types of information usually considered to be geographical include store locations and addresses of customers, although sales and product information collected at the time of a transaction is also geographically referenced. Stores are fixed by a building location while customer data become geographical once individual postcodes have been geo-coded (linked to a coordinate). The data can then be mapped relative to store locations and within boundaries of established geographical areas. ${ }^{1}$ The GIS achieves its role in business data integration by adding a "context of proximity' to these different datasets with background mapping and, since their release, new Census boundary areas.

The detailed results of the 2001 Census for Great Britain were released in 2003, providing comprehensive coverage of population statistics - both geographically and in the depth of population characteristics. They have been released in approximately 230,000 small geographical areas with several hundred associated variable counts. Clearly data volumes of this magnitude require careful selection, so key variables identified through catchment analysis can be used to gain an understanding of how existing or planned stores interact within a market area. Catchment data can be collated into regional performance indicators to facilitate new development planning. This is particularly important for new retail concepts and store locations that use Census data to analyse potential customer interaction to predict potential market size. Census data will also allow for wider network development and estimates of impacts from competition to be assessed.

How this information is reported and used within businesses by marketers depends on the aims and requirements of the end user. Planning the building of an out-of-town store, for example, requires a separate use of Census variables rather than a leaflet drop through local newspapers. Both approaches rely on the idea of a geographical area to reach a target audience or to establish a market value. The planning of a new store concentrates on a wide range of factors, and comparisons with other areas and existing stores. Analysis concentrates on levels and qualitative aspects of the wider catchment characteristics and uses the small area statistics to indicate demographic barriers to trade. A marketing campaign for the same store may seek to target consumers through a particular newspaper which is delivered to households with a certain population composition.

HIGH-STREET RETAILERS - APPLYING THE DATA

Maintaining datasets for retail planning is one of the most 


\section{Different geodata across Great Britain}

\section{Data compatibility with systems}

\section{Population weighted counts}

important drivers of any subsequent analysis drawn from a GIS database. To obtain the latest data, time was allocated to understand details of the government release plans. Learning from this included understanding costs, release dates, media formats, documentation definitions and the option of testing samples of data. This procedure ultimately led to a speedier adoption and use of the data within the organisation as it removed a reliance on third-party suppliers.

Further benefits of this approach were to gain a better understanding of themes associated with counts, definitions and omissions from the data. This knowledge led to an easier transformation of raw data into useful information for business users. Key to this approach was to create databases for England and Scotland independently. Initially this meant different variable counts were not comparable across Great Britain, along with additional storage requirements and more time to process the raw data. But given that much of the data for Northern Ireland were subsequently released at a later time, lessons learnt from separate development could be quickly reapplied.

Testing of the data was undertaken with the aim of understanding how the new output area Census geography could increase the effectiveness of the planning process, using both the updated statistics and the new boundary dataset together with existing data resources. The new data were then used with an existing GIS and incorporated into current working practices. This was achieved using existing software with new hardware to manage effectively increases in the data volumes and formats.

The approach adopted for testing involved using a demonstration output area boundary and point dataset for an urban area in southern Britain. These data from the Office for National Statistics (ONS) contained fictitious population counts as they were supplied prior to the official release date. The geographic boundary dataset was supplied in the format of a proprietary desktop GIS with Ordnance Survey coordinate data centroids - the geographical locations of the 'centres' of output areas. One key issue raised on using these data was how the output area centroids had been calculated from the constituent postcode geo-references - as both a population weighted and a geometric mean coordinate point are available.

For demographic analysis, population-weighted centroids have been identified as being of particular interest, as these would appear to be the most likely to represent a real-world location of inhabited areas. For the previous UK Census, the locations of the weighted 'centre of mass' points were identified through a non-repeatable system where individuals located the points by visual inspection. ${ }^{2}$ The process to develop the population-weighted centroids for the new output area geography involved using postcodes to find the coordinates to be attributed to the output areas. ${ }^{3}$ Having this 
New census counts

\section{Statistics from small areas}

information was useful for understanding how aggregated statistics from catchments were derived.

\section{KEY COUNTS AND CATCHMENT AREAS}

Following the release of the point and boundary output-area-level data, they were loaded into the location planning GIS database. Attribute counts from individual key statistic tables were appended to this base layer using the output area code. The business requirement was to support a retail promotion in stores which would expect an increase in trade due to the return of students to their point of study. In previous surveys students were counted at their vacation address, but in 2001 students were recorded at their term-time address. This key statistic of student numbers was appended to population-weighted point files, and collated using the GIS extraction and distance generation functionality. The number of students living around stores was calculated, allowing the identification of stores most likely to benefit from a promotion. Stores could also be classified as either having in-town populations of students or campus concentrations which would also have access to the store during term time. This example not only identified the use of the stable output area geography, but also the ease of appending new datasets to support different levels of retail planning.

Statistics calculated from an accumulation of small geographic areas rely on a mechanism for choosing these areas to get, for example, a potential total shopper count. This in turn relies on selecting the points or areas stored in a GIS to make up a catchment. Marketers can benefit from an understanding of these 'pure geographical data' when defining catchments through an automated process - such as a radius selection (a circle of fixed radius around a location) or a drive-time isochrome (an area based on drive time). This is especially true where subsequent targeting campaigns or performance analysis are supported by this aggregated information.

A catchment area can be seen as market led (with critical numbers of people requiring goods from a retailer) or centre driven (with a retail centre having a pull on the surrounding area). An actual catchment of a store is definable by mapping customer data using postcodes. When planning a new development, however, no customer data exist so characteristics from similar existing stores are used to predict future performance. Some markets are easier to define than others - either because there are pooled data available for a given market or because niche outlets exist to attract specific types of retail customer. ${ }^{4}$ Where the market for products is wide and the customer types are relatively broad, the Census variables concerning population provide a valuable insight into consumers living around new and existing retail outlets.

To establish a target population for a broad retail offer, market research can be undertaken asking people about detailed lifestyle 


\section{Boundaries fixed over time}

and shopping patterns, which in turn is used to identify characteristics available as counts from the Census data. A demand surface can be established and store location planning and marketing campaigns can then be placed in the context of the whole country. Census variables allow this matching of known consumer attributes by linking them to a geographical location to form a numerical method of evaluation.

\section{LOCATION PLANNING - 2005 AND BEYOND}

Time pressures on all business decisions will mean that many Census statistics will be aggregated to provide information rapidly. But careful use of a wide variety of geographical data can add real value to decision support when integrated with increasing volumes of business data. The identification of key demographic drivers through analysis and appropriate use with other relevant information can make it possible to predict sales levels for new units before making investment decisions. Census data are also usable for targeting resources for optimising the performance of existing stores.

The 2001 Census outputs provide more than an update on previous counts. Its new boundary geography can be used in propriety desktop systems with existing geographical data - such as store locations and postal geography boundaries. Output area boundaries which do not change regularly have been nested to form super output areas (data zones in Scotland), as shown in Figure 1. These in turn are being populated with useful government statistics. Early adopters of the new geography have benefited from postCensus releases of government national statistics. These include quantitative measures for public service planning, identifying urban areas and a Census-based geo-demographic classification.

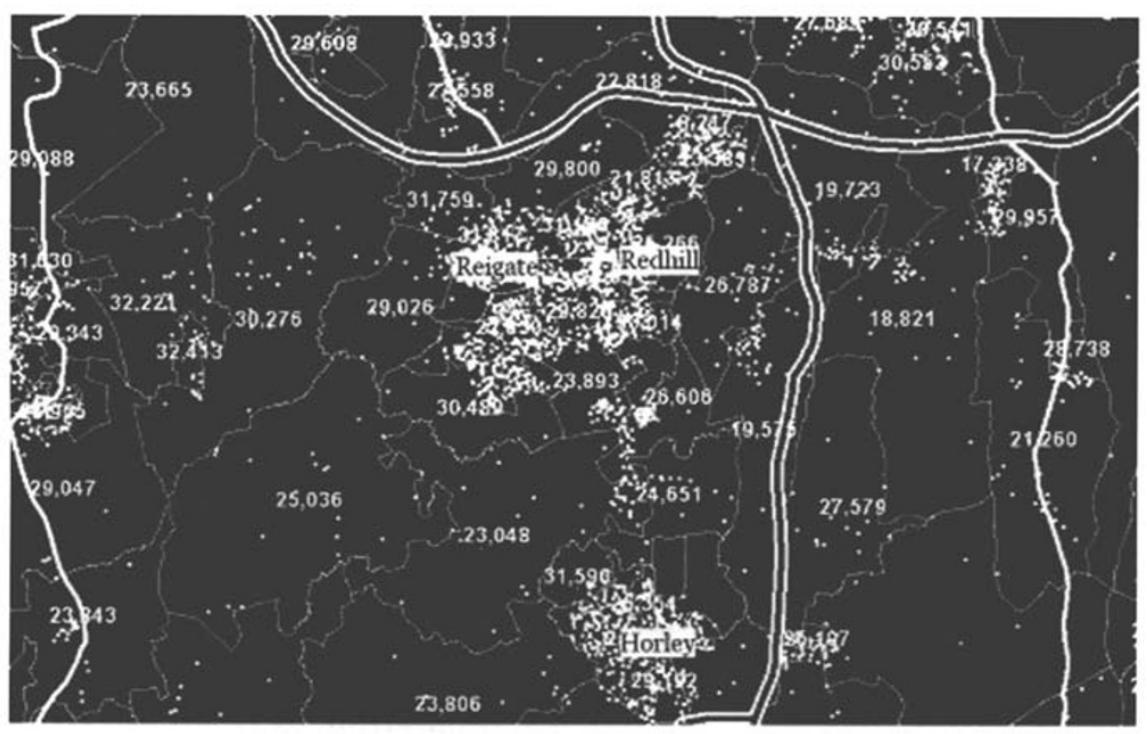

Figure 1: New geography: Postcode points and super output area boundaries 


\section{Government and commercial suppliers}

Commercial suppliers of classification products continue to fuse consumer behaviour and life-stage information, but now append them to government output area identifiers as well as to postcodes. Resulting products allow increasingly accurate information to be used in location-based planning applications. It is the government statistics that have provided the geography for these, which are being used in business, and continue to add to a wide range of important information about centres of population. Although businesses have a wide and often changing audience, marketers and managers often understand the 'language' of the Census and government counts. The testing and applying of the Census statistics as they were released assisted planning, and provided the impetus to investigate how new variables and methods of geographical analysis can be used to improve the location planning process.

\section{References}

1. Martın, D. (1995) 'Censuses and the modelling of population in GIS', in Longley, P. and Clark, G. (eds) GIS for Business and Service Planning, Geoinformation International, Cambridge, UK.

2. Martin, D. (1996) Geographic Information Systems Socioeconomic Applications, 2nd edn, Routledge, London, UK

3. Walker, N. (2004) 'The 2001 Census geography', in Dugmore, $\mathrm{K}$ and Moy, C. (eds) $A$ Guide to the 2001 Census. Essential Information for Gaining Business Advantage, The Stationery Office. London, UK.

4. Birkin. M., Clarke. G. and Clarke, M. (2003) Retall Geography and Intelligent Network Planning, John Wiley \& Sons, Chichester, UK. 